\title{
ESTUDO DE COMPOSTOS ORGÂNICOS EM LIXIVIADO DE ATERROS SANITÁRIOS POR EFS E CG/EM
}

Irajá do Nascimento Filho, Carin von Mühlen and Elina Bastos Caramão*

Instituto de Química, Universidade Federal do Rio Grande do Sul, Av. Bento Gonçalves 9500, 91501-970 Porto Alegre - RS

Recebido em 1/6/00; aceito em 14/12/00

\begin{abstract}
STUDY OF ORGANIC COMPOUNDS IN LANDFILL LEACHATE BY SPE AND GC/MSD.The main purpose of this work was the qualitative study of organic compounds in landfill leachate. The samples were collected from a sanitary landfill located at Gravataí, a southern Brazilian city, that receive both, industrial and domestic refuse. The samples were submitted to solid phase extraction (SPE) with XAD-4 resin as the stationary phase. The instrumental analysis was performed by Gas Chromatography with a Mass Spectrometry Detector (GC/MSD). The compounds achieved in the SPE extracts were tentatively identified by the GC/MS library. It was found several oxygen and nitrogen compounds like carboxylic acids, ketones, amines and amides. Sulfur compounds and phthalate esters are also identified.
\end{abstract}

Keywords: landfill leachate; gas chromatography; SPE; GC/MSD.

\section{INTRODUÇÃO}

Um sério problema que ocorre nos aterros sanitários é a formação de chorume, que é o líquido produzido pela massa orgânica do lixo durante o processo de degradação biológica. Este líquido em contato com a água da chuva, que percola a massa do aterro, gera o lixiviado, tóxico, com valores elevados de DBO (Demanda Bioquímica de Oxigênio) e DQO (Demanda Química de Oxigênio), traços de metais dissolvidos e amônia ${ }^{1}$.

No Brasil, o chorume é coletado nos aterros sanitários e transportado, em caminhões pipa, para Estações de Tratamento de Esgotos (ETEs), onde é submetido à degradação microbiológica. Após isso, o chorume é lançado, juntamente com o esgoto tratado em águas superficiais.

Uma vez que são desconhecidas as identidades dos compostos presentes no chorume, não há como prever se este tratamento é efetivo.

A identificação de compostos orgânicos em chorume é uma preocupação que vem motivando a pesquisa científica em nível mundial. Como exemplos podem ser citados trabalhos dedicados à identificação de carcinógenos ${ }^{2}$, compostos orgânicos voláteis em atmosfera de aterros sanitários com e sem piscina para coleta de chorume ${ }^{3}$, estrógenos ambientais ${ }^{4}$, potencial de lixiviação de plastificantes como o dietilhexilftalato ${ }^{5}$, testes de toxicidade $^{6}$ e o desenvolvimento de sistemas de alto vácuo para a extração de orgânicos voláteis ${ }^{7}$.

Por outro lado, no Brasil este assunto não tem despertado muito interesse entre os Químicos Ambientalistas. Considerando-se as reuniões anuais da Sociedade Brasileira de Química como um indicador apropriado das tendências de linhas de pesquisa no Brasil, pode-se verificar que entre os anos de 1993 e 2000, dos 618 trabalhos publicados na seção de Química Ambiental dos livros de resumos, apenas um trata especificamente da identificação de compostos orgânicos em chorume ${ }^{8}$, tornando evidente a carência de informações sobre este assunto, disponíveis na literatura científica brasileira.

Sendo assim, os objetivos iniciais deste trabalho foram a aplicação da técnica de EFS para extração de compostos orgânicos de baixa e média polaridade, presentes no lixiviado de aterros sanitário, utilizando-se resina polimérica XAD-4 como fase estacionária e a identificação, por tentativa, dos componentes do extrato orgânico, via biblioteca do sistema CG/EM.

\section{PARTE EXPERIMENTAL}

\begin{abstract}
Amostras
Foram utilizadas amostras de chorume bruto provenientes do aterro sanitário da cidade de Gravataí (RS), com piscina para recolhimento do lixiviado, que recebe tanto lixo industrial quanto domiciliar, sob responsabilidade do DMLU (Departamento Municipal de Limpeza Urbana) de Porto Alegre. As amostras foram coletadas em frascos de vidro âmbar com tampa forrada com alumínio. Assim que chegaram ao laboratório, as amostras tiveram seu $\mathrm{pH}$ aferido $(\sim 7)$, foram filtradas em funil de vidro sinterizado e guardadas em geladeira a $4^{\circ} \mathrm{C}$, ao abrigo da luz até o momento das extrações (no máximo $24 \mathrm{~h}$ após a coleta).
\end{abstract}

\section{Reagentes e Solventes}

Todos os reagentes e solventes foram adquiridos em grau p.a. (Merck ou similar) e, quando necessário, bidestilados em equipamento de vidro.

A resina poliestireno/divinilbenzeno XAD-4 (20-50 mesh, superfície ativa: $750 \mathrm{~m}^{2} / \mathrm{g}$, diâmetro médio de poro: $50 \AA$ A) foi purificada através de extração em Soxhlet com n-hexano (4 horas), acetona (4 horas) e diclorometano (5 horas). A lã de vidro utilizada nas extrações também foi extraída em Soxhlet com diclorometano (4 horas). Todo material de vidro utilizado nos ensaios foi lavado com n-hexano, acetona e diclorometano e seco em forno por 4 horas. Não foram utilizados materiais de plástico ou borracha que entrassem em contato direto com as amostras ou solventes.

\section{Análise Instrumental}

A otimização da metodologia de EFS foi realizada em um cromatógrafo à gás HP 5890, equipado com injetor operando no modo de divisão de fluxo na razão de 1:50, integrador mecânico e detector de ionização de chama (DIC). A identificação dos compostos obtidos por EFS foi realizada por comparação com os espectros armazenados na biblioteca de um equipamento Shimadzu GC 17A, GC/MS 5050A, também equipado com injetor operando no modo de divisão de fluxo na razão de 1:50. 


\section{DESENVOLVIMENTO DE METODOLOGIA DE EFS}

\section{Preparação da Coluna de EFS}

A coluna de duas vias para EFS, feita em nosso laboratório (Figura 1) foi recheada com $1 \mathrm{~g}$ de fase estacionária e seguiuse o condicionamento com a eluição de $5 \mathrm{~mL}^{\text {de }}$ metanol $^{9}$, e nova eluição com $15 \mathrm{~mL}$ de água destilada e deionizada ${ }^{9}$.

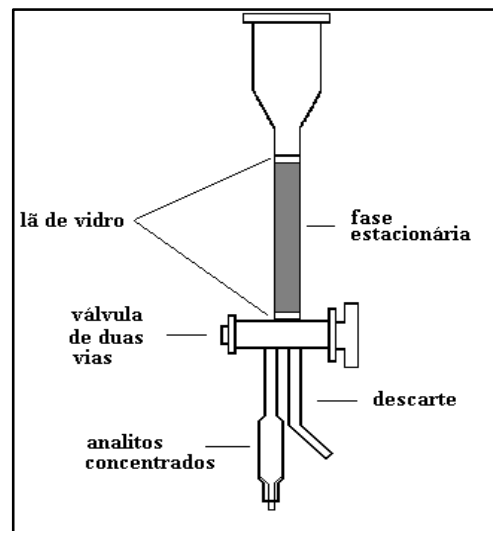

Figura 1. Válvula de duas vias utilizada nos ensaios de EFS.

\section{Metodologia de Extração}

a) pesou-se $1 \mathrm{~g}$ de fase estacionária;

b) adicionou-se $15 \mathrm{~mL}$ de água destilada e deionizada à amostra e a mistura foi agitada por 15 minutos;

c) a fase estacionária foi então transferida para a coluna de vidro observando-se que o leito de fase sólida não ficasse seco;

d) as amostras foram então eluídas na coluna e, após isso, os analitos foram extraídos com $20 \mathrm{~mL}$ de uma mistura de metanol/acetona (2mL: $18 \mathrm{~mL})$. Após a eluição da amostra, o excesso de água presente na fase estacionária foi retirado através de um sistema de sucção utilizando uma bomba de vácuo; os extratos foram passados através de uma coluna de sulfato de sódio anidro e os solventes foram evaporados sob fluxo de nitrogênio ultrapuro e analisados no sistema CG/EM nas condições apresentadas na Tabela 1.

Tabela 1. Condições de análise no sistema CG/EM das frações obtidas por EFS de lixiviado de aterro sanitário.

\begin{tabular}{lc}
\hline Parâmetro & Condições \\
\hline Temperatura do injetor & $280^{\circ} \mathrm{C}$ \\
Temperatura da interface & $280^{\circ} \mathrm{C}$ \\
Temperatura inicial & $70{ }^{\circ} \mathrm{C}(3 \mathrm{~min})$ \\
Rampa e aquecimento 1 & $3{ }^{\circ} \mathrm{C} / \mathrm{min}$ \\
Temperatura final 1 & $200^{\circ} \mathrm{C}$ \\
Rampa de aquecimento & $10^{\circ} \mathrm{C} / \mathrm{min}$ \\
Temperatura final 2 & $280^{\circ} \mathrm{C}$ \\
Tempo final & $5 \mathrm{~min}$ \\
Fluxo do gás de arraste(He) & $1 \mathrm{~mL} / \mathrm{min}$ \\
coluna & $\mathrm{HP}-1,30 \mathrm{~m} \mathrm{x}$ \\
& $0,25 \mathrm{~mm} \mathrm{x} 0,25 \mathrm{~mm}$ \\
Modo de análise & $\mathrm{SCAN}($ varredura \\
& de espectros) \\
Modo de ionização & Impacto eletrônico \\
Modo de injeção & a 70 eV \\
\hline
\end{tabular}

\section{RESULTADOS}

A Figura 2 apresenta os cromatogramas do íon total para os extratos orgânicos de lixiviado de aterro sanitário, obtidos por EFS utilizando-se a mistura metanol/acetona como eluente. Os picos assinalados na Figura 2 foram tentativamente identificados pela biblioteca do sistema CG/EM e os resultados estão apresentados na Tabela 2.

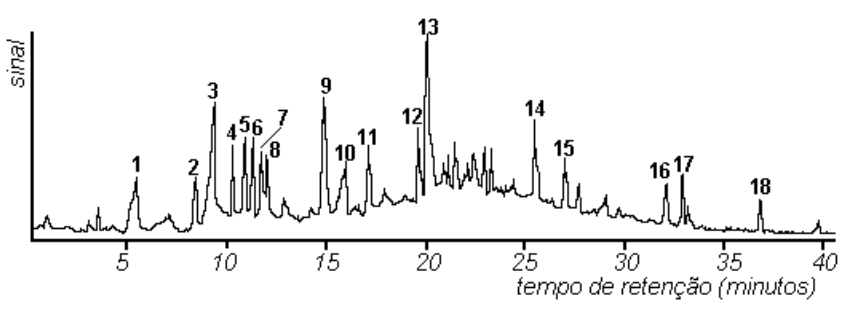

Figura 2. Cromatograma de Íon Total da fração obtida por EFS de lixiviado de aterro sanitário com a mistura metanol/acetona

Tabela 2. Compostos tentativamente identificados (via biblioteca do sistema CG/EM) dos picos assinalados na figura 2.

\begin{tabular}{|c|c|c|c|}
\hline Pico & Composto & $\begin{array}{l}\text { Peso } \\
\text { molecular }\end{array}$ & $\begin{array}{l}\text { Grupo } \\
\text { funcional }\end{array}$ \\
\hline 1 & $\begin{array}{l}\text { ácido ciclohexano } \\
\text { carboxílico }\end{array}$ & 128 & $-\mathrm{COOH}$ \\
\hline 2 & hexahidro azepinona & 113 & $\begin{array}{l}\mathrm{R}-\mathrm{CO}-\mathrm{R}_{1} \\
\quad-\mathrm{NR}_{2}\end{array}$ \\
\hline 3 & ácido fenil acético & 136 & $-\mathrm{OH}$ \\
\hline 4 & hidrato de terpinol & 172 & $-\mathrm{OH}$ \\
\hline 5 & terpenediol & 170 & $-\mathrm{OH}$ \\
\hline 6 & acetoxilinalol & 212 & $-\mathrm{OH}$ \\
\hline 7 & ácido benzenopropanóico & 150 & $-\mathrm{COOH}$ \\
\hline 8 & ácido metiléster noninóico & 168 & $-\mathrm{COOH}$ \\
\hline 9 & $\begin{array}{l}\text { trimetil-ciclohexeno } \\
\text {-carboxaldeído }\end{array}$ & 152 & $-\mathrm{COH}$ \\
\hline 10 & N-etilfenil-acetamida & 163 & $\mathrm{ph} ;-\mathrm{COO}-\mathrm{NR}_{2}$ \\
\hline 11 & $\mathrm{C}_{2}$ - benzosixazola & 147 & $=\mathrm{N}-\mathrm{O}-(\mathrm{cic})$ \\
\hline 12 & $\mathrm{C}_{3}$ - benzenosulfonamida & 199 & $-\mathrm{COO}-\mathrm{NH}_{2}$ \\
\hline 13 & benzotiazolona & 151 & $\mathrm{R}-\mathrm{CO}-\mathrm{R}_{1}$ \\
\hline 14 & isobutil ftalato & 278 & $\mathrm{ph} ;-\mathrm{COOC}_{4}$ \\
\hline 15 & C4-purina-dihidro-diona & 208 & $\mathrm{R}-\mathrm{CO}-\mathrm{R}_{1} ;-\mathrm{NR}_{2}$ \\
\hline 16 & bisfenol A & 228 & $\mathrm{ph} ;-\mathrm{OH}$ \\
\hline 17 & diaza-dicetocil-tetradecano & 226 & $\mathrm{R}_{2}-\mathrm{N}-\mathrm{N}-\mathrm{R}_{2}$ \\
\hline 18 & dioctil adipato & 370 & -COO- \\
\hline
\end{tabular}

Os resultados dos ensaios de EFS revelaram a presença de um grande número de compostos pertencentes a variadas funções químicas, especialmente aquelas contendo átomos de oxigênio, nitrogênio e enxofre.

Cetonas, álcoois, compostos nitrogenados e ácidos carboxílicos são substâncias normalmente encontradas em lixiviados de aterros sanitários, provavelmente resultantes da degradação da matéria orgânica.

Entretanto, a presença de outros compostos de largo emprego industrial e com reconhecida ação ambiental, indica que a degradação do material orgânico por ação bacteriológica não é 
eficiente, contribuindo para um aumento do potencial toxicológico do chorume produzido. O bisfenol (pico 16 na Figura 2) é normalmente utilizado para a fabricação de resinas epoxi, aplicadas em tintas, colas, plásticos termorrígidos e material de revestimento ${ }^{10}$; os ftalatos (pico 14 na Figura 1) são utilizados na fabricação de embalagens, tintas, tecidos ${ }^{4}$, etc. Tanto o bisfenol com os ftalatos são considerados importantes estrógenos ambientais ${ }^{4}$

Outro composto tentativamente identificado, a benzotiazolona (pico 13 na Figura 1), pode ser um derivado da decomposição de antioxidantes geralmente usados nas indústrias de pneus e borrachas sintéticas, enquanto o $\mathrm{C}_{2}$-bensixazol (pico 11 na Figura 1) pode ser um derivado do princípio ativo de um medicamento conhecido comercialmente como risperidona ou risperidal, uma droga antipsicótica usada no tratamento da esquizofrenia.

\section{CONCLUSÕES}

A presença de compostos orgânicos suspeitos de atuarem como estrógenos ambientais (ftalatos e bisfenol), compostos de ação antioxidante (benzotiazolona) e compostos que atuam como princípios ativos de medicamentos (bensixazol) nas amostras estudadas são fatores preocupantes com relação ao meio ambiente, uma vez que os limites de tolerância em ambientes abertos (aterros sanitários) e os efeitos de exposição de longo prazo (contaminação dos mananciais de água potável) a estes compostos são desconhecidos.

Por outro lado a presença de compostos de menor importância ambiental como ácidos carboxílicos também deve ser avaliada com cuidado, pois é sabido que estes compostos podem promover a lixiviação de metais pesados dos resíduos sólidos ou do próprio terreno onde se encontra o aterro, para o chorume.

Desta forma, a eficiência dos métodos convencionais de tratamento do chorume em função da presença de compostos de difícil degradação microbiológica (plastificantes) ou resistentes aos métodos clássicos de degradação de matéria orgânica por oxidação (antioxidantes), merece maior estudo. Várias propostas de tratamento do lixiviado têm sido desenvolvidas nos últimos anos, destacando-se como mais promissora a utilização de um processo misto, composto de etapas anaeróbias e aeróbias intercaladas e enzimas específicas, fixas em suportes.
Estes processos podem ser destrutivos, ou seja, reduzem ou até eliminam os contaminantes transformando-os em materiais inertes, ou de recuperação de matéria prima, ou seja, aqueles que recuperam os produtos químicos presentes no chorume para posterior utilização.

Por outro lado, para qualquer dos processos de tratamento, é de fundamental importância a identificação das fontes geradoras destes compostos visando ou a sua eliminação (modificações de processos nas fontes geradoras ou no tratamento do chorume) ou seu reaproveitamento como insumos para a indústria química (extração a partir do chorume).

\section{AGRADECIMENTOS}

Os autores agradecem ao Departamento Municipal de Limpeza Urbana de Porto Alegre pela cessão das amostras e aos órgão de fomento à pesquisa CAPES, FAPERGS e CNPq.

\section{REFERÊNCIAS}

1. Murray, J. P.; Rouse, J. V.; Carpenter, A. B.; Water Res. 1981, 15, 745 .

2. McArdle, J. L.; Arozarena, M. M., "Treatment of Hazardous Waste Leachate”, Noyes Data Corporation, New Jersey, USA, 1988.

3. James, K. J.; Stack, M. A.; Chemosphere 1997, 34, 1713.

4. Baird, C.; Environmental Chemistry; W. H. Freeman and Company; New York, 1999, p. 368.

5. Baurer, M. J.; Herrmann, R.; Sci. Total Environ. 1997, 49, 208.

6. Bernard, C.; Guido, P.; Colin, J.; Anne, L. D.; Chemosphere 1996, 33, 2303.

7. Khare, M.; Dondere, N. C.; Environ. Sci. Technol. 1977, $11,814$.

8. Nascimento, I. F.; von Mühlen, C.; Caramão, E. B.; $22^{a}$ Reunião Anual da SBQ, Poços de Caldas, MG, 1999.

9. Castilho, M. C.; Ramos, F.; Silveira, I. N.; Revista Portuguesa de Farmácia 1997, 4, 155.

10. Möder, M.; Popp, P.; Pawliszyn, J.; J. Microcolumn Sep. 1998, 10, 225. 